\title{
Highly selective nanocomposite sorbents for the specific recognition of S-ibuprofen from structurally related compounds
}

\author{
M. P. Sooraj ${ }^{1} \cdot$ Beena Mathew ${ }^{1}$
}

Received: 18 March 2015/Accepted: 22 June 2015/Published online: 10 July 2015

(c) The Author(s) 2015. This article is published with open access at Springerlink.com

\begin{abstract}
The aim of the present work was to synthesize highly homogeneous synthetic recognition units for the selective and specific separation of S-ibuprofen from its closely related structural analogues using molecular imprinting technology. The molecular imprinted polymer wrapped on functionalized multiwalled carbon nanotubes (MWCNT-MIP) was synthesized using S-ibuprofen as the template in the imprinting process. The characterization of the products and intermediates were done by FT-IR spectroscopy, PXRD, TGA, SEM and TEM techniques. The high regression coefficient value for Langmuir adsorption isotherm $\left(R^{2}=0.999\right)$ showed the homogeneous imprint sites and surface adsorption nature of the prepared polymer sorbent. The nano-MIP followed a second-order kinetics $\left(R^{2}=0.999\right)$ with a rapid adsorption rate which also suggested the formation of recognition sites on the surface of MWCNT-MIP. MWCNT-MIP showed $83.6 \%$ higher rebinding capacity than its non-imprinted counterpart. The higher relative selectivity coefficient $\left(k^{\prime}\right)$ of the imprinted sorbent towards S-ibuprofen than that for its structural analogues evidenced the capability of the nano-MIP to selectively and specifically rebind the template rather than its analogues.
\end{abstract}

Keywords Molecular imprinting · Nanocomposites · Adsorption · S-Ibuprofen · Morphology

Beena Mathew

beenamj@yahoo.com

1 School of Chemical Sciences, Mahatma Gandhi University, Kottayam 686560, Kerala, India

\section{Introduction}

Molecular imprinting is a concept, which involves the creation of highly specific recognition sites usually within polymer matrix. Here, functional monomers and appropriate amount of crosslinkers are polymerized in the presence of template molecules. Subsequent removal of the template creates a template-specific binding site within the polymer matrix (Vasapollo et al. 2011; Lendoiro et al. 2014). These cavities are capable of recognizing the target molecule from its structurally related compounds. At present, molecular imprinted polymers (MIPs) are widely used in many areas of science such as sensing (Wren et al. 2014), food sciences (Whitcombe et al. 1997; Perreten et al. 1997), separation sciences (McCluskey et al. 2007; Zhang et al. 2012), drug delivery (Puoci et al. 2013) and isolation (Kyzas et al. 2015), solid phase extraction (Özcan and Demirli 2014; Zarejousheghania et al. 2014) and detection of pollutants (Jenkins et al. 2001; Kyzas and Bikiaris 2014; Kyzas et al. 2014). However, MIPs prepared by conventional manner do have some restrictions such as incomplete template removal, slow kinetics, less binding capacity, poor site accessibility (Turner et al. 2006), etc. In order to overcome these difficulties, high surface-to-volume ratio surface-imprinted polymers which provide a complete extraction of the template molecules have been developed (Rezaei and Rahmanian 2012).

Nowadays nanomaterials are established to be very good supporting material for surface-imprinting techniques. Among them, carbon nanotubes (CNTs) have proven quite successful support materials for MIPs because of their strong interactions, stability under drastic conditions and large surface area (Pan et al. 2011). If the MIPs are prepared on the surface of multiwalled carbon nanotubes (MWCNTs), it would provide large surface-to-volume 
ratio to the MIP. The rebinding cavities in the surface of the composite would improve the accessibility of target molecule and thus reduce the time of rebinding (Sooraj and Mathew 2014).

We present here the synthesis of molecular imprinted composite sorbents (nano-MIP) for the selective recognition and separation of S-ibuprofen [2-(4-isobutylphenyl) propionic acid] hitherto abbreviated as S-IBU, a non-steroidal anti-inflammatory, antipyretic drug widely used in the treatment of pain and inflammation, from its structurally similar compounds ketoprofen (KET) and naproxen (NAP). The MIP was prepared on the vinyl-functionalized surface of MWCNT with S-ibuprofen as template, vinyl imidazole (VIZ) as functional monomer, EGDMA as cross-linker and AIBN as initiator. Subsequent removal of template molecules using a suitable solvent yields MWCNT-MIP with surface-imprinted cavities capable of selectively and specifically binding S-IBU. The rebinding parameters that can influence the extent of template rebinding were then optimized. Adsorption experiments were used for the monitoring of selective recognition of S-IBU by MWCNTMIP. Adsorption kinetics and isotherms of MWCNT-MIP were also studied in detail. The composition of MWCNTMIP was analyzed using FT-IR, powder XRD and thermogravimetric analysis and their morphologies were observed using scanning electron microscopic and transmission electron microscopic techniques.

\section{Experimental}

\section{Materials}

MWCNT was obtained from Reinste Nano Ventures Private Limited, India. 1-Vinyl imidazole (98\%), 2-hydroxyethyl methacrylate (HEMA 98\%), ethylene glycol dimethacrylate (EGDMA $98 \%$ ) and all solvents (HPLC grade) were obtained from Merck, India. S-IBU (99\%), KET (99 \%), NAP (99\%), 2,2-azobisisobutyronitrile (AIBN) and thionylchloride $\left(\mathrm{SOCl}_{2}\right)$ were purchased from Sigma Aldrich. All the chemicals and solvents were used without further purification. Doubly distilled water was used throughout the course of experiments as and when required.

\section{Methods}

Fourier-transform infrared (FT-IR) spectroscopic measurements were performed on a Perkin-Elmer 400 FT-IR spectrophotometer in the range $4000-400 \mathrm{~cm}^{-1}$. Ultraviolet-visible (UV-vis) absorption spectra were investigated on a Shimadzu UV-vis spectrophotometer model 2450 using chloroform as solvent. A thermogravimetric analyzer (NETZSCHSTA449C) was used to measure the thermostability of the products and intermediates from room temperature to $800{ }^{\circ} \mathrm{C}$ at a constant heating rate of $10{ }^{\circ} \mathrm{C} /$ min in an inert atmosphere. Morphological studies were done on a JEOL-JSM-6390A scanning electron microscope (SEM) and JEOL-2100 model high-resolution tunnelling electron microscope (HR-TEM).

\section{Preparation of vinyl-functionalized MWCNT (MWCNT-CH=CH )}

Concentrated nitric acid (AnalaR grade, $70 \mathrm{~mL}$ ) was added to $1 \mathrm{~g}$ of purified MWCNT (Shen et al. 2008) in a roundbottom flask followed by sonication for about $15 \mathrm{~min}$ in a bath-type sonicator at $40 \mathrm{kHz}$. The mixture was refluxed for $7.5 \mathrm{~h}$ at $80{ }^{\circ} \mathrm{C}$ under vigorous stirring. It was diluted with excess amount of deionized water $(3 \mathrm{~L})$ and filtered through $0.2 \mu \mathrm{m}$ PTFE membrane to separate the solid components. Washing was continued until the $\mathrm{pH}$ of the supernatant became the same as that of deionized water. The obtained solid product was dried under vacuum at $60{ }^{\circ} \mathrm{C}$ for $24 \mathrm{~h}$, yielding MWCNT-COOH.

Acid-treated MWCNT (250 mg) was reacted with $10 \mathrm{~mL}$ of $\mathrm{SOCl}_{2}$ in a reaction flask equipped with reflux condenser containing $15 \mathrm{~mL}$ THF (GR, Merck India). The reaction mixture was maintained at $60{ }^{\circ} \mathrm{C}$ for $24 \mathrm{~h}$ under vigorous stirring. After cooling, the mixture was repeatedly washed with anhydrous THF several times until the browncolored supernatant became colorless. The solid product was separated by centrifugation at $14,000 \mathrm{rpm}$, and then dried under vacuum at $60^{\circ} \mathrm{C}$ for $18 \mathrm{~h}$. Vinyl functionalization of MWCNT-COCl was done using $3 \mathrm{~mL}$ 2-hydroxy ethylmethacrylate (Kumar et al. 2008).

\section{Synthesis of S-ibuprofen (IBU) imprinted and non-imprinted polymers on MWCNT (MWCNT-MIP/NIP)}

$0.5 \mathrm{mmol}$ of 1-vinylimidazole (VIZ), $0.1 \mathrm{mmol} \mathrm{S-IBU,}$ $1 \mathrm{mmol}$ EGDMA and $50 \mathrm{mg}$ of the initiator AIBN were accurately weighed into a $100 \mathrm{ml}$ round-bottomed flask equipped with a reflux condenser, $25 \mathrm{~mL}$ chloroform was added to dissolve the mixture and was then ultrasonicated for $20 \mathrm{~min}$ to ensure absolute association of the S-IBU molecule with VIZ. Finally, $0.075 \mathrm{~g}$ of MWCNT-CH= $\mathrm{CH}_{2}$ was uniformly dispersed into the mixture. The reaction mixture was refluxed at $70{ }^{\circ} \mathrm{C}$ for $24 \mathrm{~h}$ under nitrogen atmosphere. The resulting polymer composite was collected by filtration, ground well and washed repeatedly with chloroform until the template molecule could not be detected in the eluent by UV-vis spectroscopy 
Fig. 1 Synthesis route of MWCNT-MIP
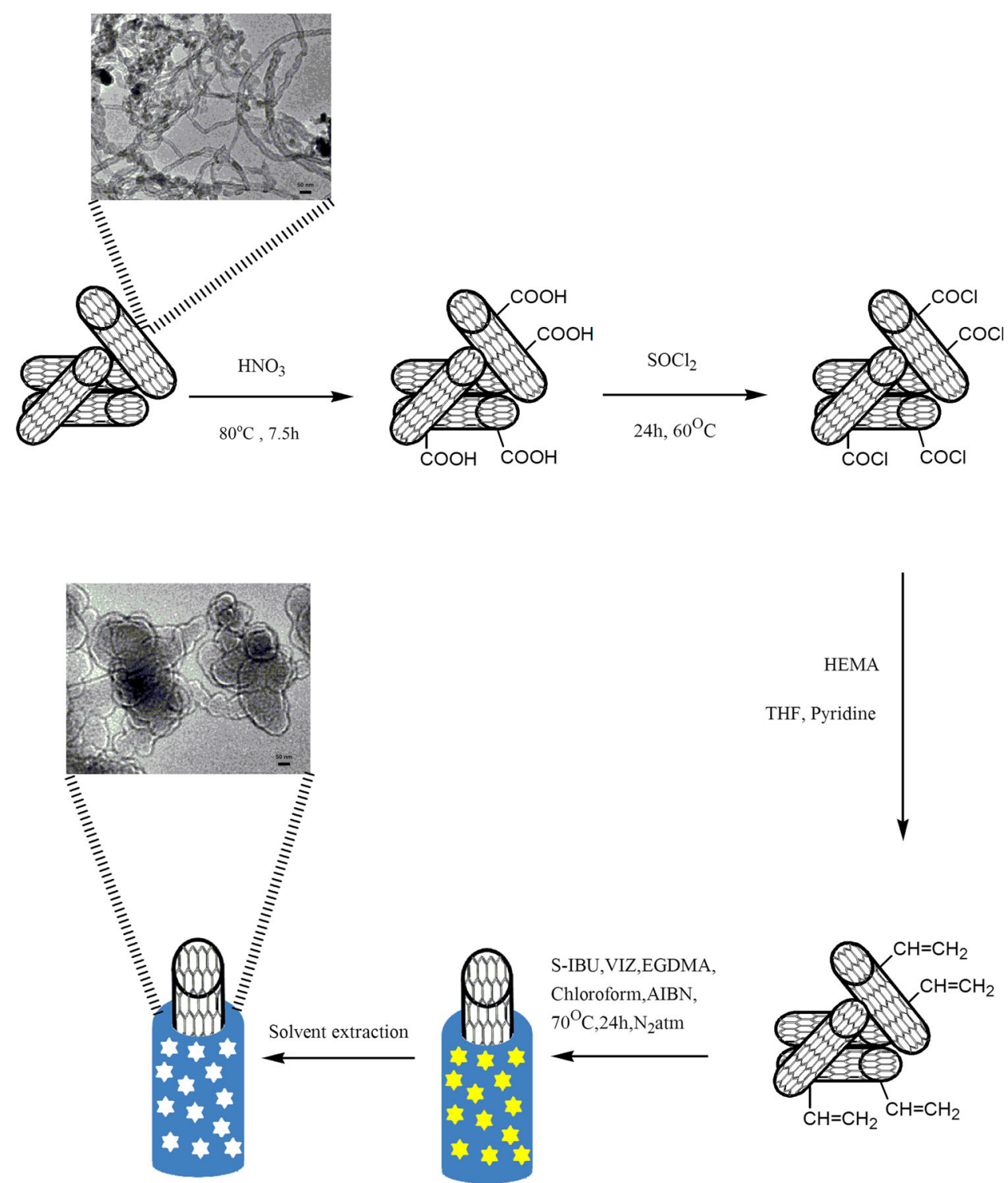

S-IBU,VIZ,EGDMA,

Chloroform,AIBN,

$70^{\mathrm{O}} \mathrm{C}, 24 \mathrm{~h}, \mathrm{~N}_{2} \mathrm{~atm}$

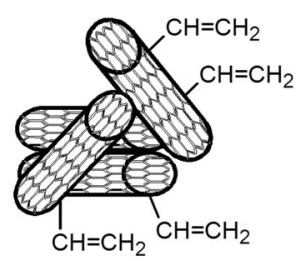

$\left(\lambda_{\max }=272 \mathrm{~nm}\right)$ (Fig. 1). The obtained sorbent was dried under vacuum for $24 \mathrm{~h}$ before use. The non-imprinted nanostructured polymer was also prepared following the above procedure but in the absence of S-IBU molecules.

\section{Effect of concentration}

To determine the rebinding behavior of MWCNT-MIPs/ NIPs towards the template, $8 \mathrm{~mL}$ of S-IBU solution having different concentrations ranging from 0.4 to $4.8 \mathrm{mmol} \mathrm{L}^{-1}$ were taken into shaking bottles made of borosil glass. Then $0.01 \mathrm{~g}$ of nanostructured sorbents was added into it. These mixtures were batch equilibrated on a water bath shaker at $28{ }^{\circ} \mathrm{C}$ and after reaching binding equilibrium (about $4 \mathrm{~h}$ ) the mixture was centrifuged to separate the sorbent.
Concentration at which maximum amount of S-IBU bound by the polymer was determined using the equation:

$Q_{\mathrm{e}}=\left(C_{\mathrm{o}}-C_{\mathrm{e}}\right) V / M$

where $C_{\mathrm{o}}\left(\mathrm{mmol} \mathrm{L}^{-1}\right)$ and $C_{\mathrm{e}}\left(\mathrm{mmol} \mathrm{L}^{-1}\right)$ are the initial and equilibrium concentration, $V(\mathrm{~L})$ is the volume of aspirin solution and $M(\mathrm{~g})$ is the weight of the sorbent.

\section{Effect of sorbent dosage}

The influence of adsorbent dosage on S-IBU sorption was determined by adding varying masses (5-20 mg) of MWCNT-MIP/NIP to the optimized concentration of

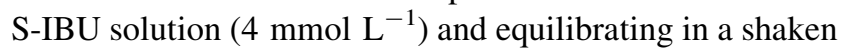
bed for $4 \mathrm{~h}$. The amount of S-IBU bound by the polymer composite sorbents was calculated using Eq. (1). 


\section{Adsorption isotherm study}

Adsorption of template was investigated in batch experiments. For this $0.01 \mathrm{~g}$ of the imprinted nanocomposite sorbents were equilibrated with $8 \mathrm{~mL}$ of varying concentrations of S-IBU ranging from 0.4 to $4 \mathrm{mmol} \mathrm{L}^{-1}$. After $4 \mathrm{~h}$ equilibration the sorbents were separated by centrifugation. From the UV-vis absorption data at $\lambda_{\max }=272$ $\mathrm{nm}$, equilibrium concentration of the template and the adsorption capacity $\left(Q_{\mathrm{e}}\right)$ of the adsorbent was calculated (Eq. 1). The theoretical adsorption capacity value for the adsorbent can be calculated from Langmuir (2) and Freundlich (3) isotherm models (Ho 2006).

$Q_{\mathrm{e}}=Q_{\mathrm{m}} K_{\mathrm{a}} C_{\mathrm{e}} / 1+K_{\mathrm{a}} C_{\mathrm{e}}$

$Q_{\mathrm{e}}=K_{\mathrm{F}} C_{\mathrm{e}}^{1 / n}$

However, the linear least-squares method with linearly transformed isotherm equations is now widely applied to confirm experimental data and isotherms using coefficients of determination. Herein the theoretical adsorption capacity value for the adsorbent was calculated using one of the linearized forms of Langmuir (4) and Freundlich (5) equations:

$$
\begin{aligned}
& \left(1 / Q_{\mathrm{e}}\right)=\left(1 / Q_{\mathrm{m}}\right)+\left(1 / Q_{\mathrm{m}} K_{\mathrm{a}}\right) \times\left(1 / C_{\mathrm{e}}\right) \\
& \log \left(Q_{\mathrm{e}}\right)=\log K_{\mathrm{F}}+1 / n \log C_{\mathrm{e}}
\end{aligned}
$$

where $C_{\mathrm{e}}\left(\mathrm{mmol} \mathrm{L}^{-1}\right)$ and $Q_{\mathrm{e}}\left(\mathrm{mmol} \mathrm{g}^{-1}\right)$ represents the concentration of S-IBU and the amount adsorbed at adsorption equilibrium, $Q_{\mathrm{m}}\left(\mathrm{mmol} \mathrm{g}^{-1}\right)$ and $K_{\mathrm{a}}\left(\mathrm{Lm} \mathrm{g}^{-1}\right)$ are the theoretical maximum adsorption capacity and Langmuir equilibrium constant related to the theoretical maximum adsorption capacity and energy of adsorption, respectively. $K_{\mathrm{F}}$ and $n$ are the Freundlich constants, which indicate the adsorption capacity and adsorption intensity, respectively. The parameters of each model found from the slope and intercept of respective plots were compared using regression analysis.

\section{Kinetic studies}

In order to study further the adsorption kinetics of S-IBU onto the nanocomposite sorbent and its rate-controlling steps, a kinetic examination was conducted. A series of $8 \mathrm{~mL} 4 \mathrm{mmol} \mathrm{L}^{-1}$ samples of S-IBU was treated with $10 \mathrm{mg}$ of MWCNT-MIP. The sorbents were separated at different time intervals from the solution by centrifugation (1600 rpm) followed by filtration. Concentration of S-IBU in the supernatant was determined at $272 \mathrm{~nm}$ using UVvis. spectrophotometer.

Langergen first order rate model (Lagergren 1898) was used for the analysis of sorption kinetics. The equations involved are as below: $\mathrm{d} Q_{t} / \mathrm{d}_{t}=k_{1}\left(Q_{\mathrm{e}}-Q\right)$

where $k_{1}\left(\mathrm{~min}^{-1}\right)$ is the rate constant of pseudo-first-order sorption, $Q_{t}$ denotes the amount of IBU sorption $\left(\mathrm{mmol} \mathrm{g}^{-1}\right)$ at time $t(\mathrm{~min})$ and $Q_{\mathrm{e}}$ denotes the amount of $\mathrm{S}$-IBU sorption $\left(\mathrm{mmol} \mathrm{g}^{-1}\right)$ at equilibrium. After definite integration and applying the initial conditions $Q_{t}=0$ at $t=0$ and $Q_{t}=Q_{t}$ at $t=t$, Eq. (6) becomes:

$\ln \left(Q_{\mathrm{e}}-Q_{t}\right)=\ln \left(Q_{\mathrm{e}}\right)-k_{1} t$.

In addition, a pseudo-second-order equation proposed by Ho and McKay (Ho and McKay 1998) based on the assumption that the adsorption follows second-order chemisorption was also used. The equation may be expressed in the form:

$\mathrm{d} Q_{t} / \mathrm{d}_{t}=k_{2}\left(Q_{\mathrm{e}}-Q\right)^{2}$,

where $k_{2}$ is the rate constant of pseudo-second-order sorption. Integrating Eq. (6) and applying the initial conditions,

$1 /\left(Q_{\mathrm{e}}-Q_{t}\right)=\left(1 / Q_{\mathrm{e}}\right)+k_{2} t$

or equivalently

$\left(t / Q_{t}\right)=\left(1 / k_{2} Q_{\mathrm{e}}^{2}\right)+t / Q_{\mathrm{e}}$

From the plots $\ln \left(Q_{\mathrm{e}}-Q_{t}\right)$ vs $t$ and $t / Q_{t}$ vs $t$ the values of maximum amount of template bound at equilibrium $\left(Q_{\mathrm{e}}\right)$ and respective rate constants were calculated.

\section{Selectivity studies}

The selective recognition ability of the surface-imprinted composite sorbent towards S-IBU was evaluated through the competitive adsorption experiments towards S-IBU, KET and NAP. During the course of experiment the optimum concentrated $\left(4 \mathrm{mmol} \mathrm{L}{ }^{-1}\right)$ solutions of the template and structural analogues were used. The procedure was same as that of adsorption studies. The extent of selectivity was found to depend not only on the number and complementarity of the imprinted cavities, but also their rebinding ability; this effect was calculated (Cao et al. 2014) using the equation:

$K_{\mathrm{d}}=\left(C_{\mathrm{i}}-C_{\mathrm{f}}\right) V / M C_{\mathrm{f}}$,

where $K_{\mathrm{d}}\left(\mathrm{Lg}^{-1}\right)$ is the distribution coefficient, $C_{\mathrm{i}}$

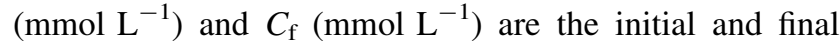
template concentrations, respectively, $V$ is the volume of the solution (L) and $M(\mathrm{~g})$, the mass of sorbent used.

The selectivity coefficient $(k)$ and relative selectivity coefficient $\left(k^{\prime}\right)$ were determined (Cao et al. 2014) using Eqs. (12) and (13): 
$k=K_{\text {template }} / K_{\text {analogue }}$

$k^{\prime}=K_{\mathrm{MIP}} / K_{\mathrm{NIP}}$

\section{Robustness and reusability}

S-IBU adsorption and desorption study was done over a period of 8 months using the same polymer for testing its robustness and reusability. $8 \mathrm{~mL}, 4 \mathrm{mmol} \mathrm{L}^{-1}$ solution of $\mathrm{S}$-IBU was taken in a shaking bottle. To this $10 \mathrm{mg}$ each of MWCNT-MIP/NIP were incubated at $28{ }^{\circ} \mathrm{C}$ for $4 \mathrm{~h}$. Then, the contents were centrifuged at $14,000 \mathrm{rpm}$ to remove the polymer composite sorbents and the amount of bound $\mathrm{S}$-IBU in the supernatant liquid was monitored by UV-vis. spectroscopy. The polymers were washed with chloroform and dried under vacuum for the next application.

\section{Solubility test}

The solubility of MWCNT, MWCNT-COOH and MWCNT-MIP were checked using chloroform as the solvent. $0.01 \mathrm{~g}$ of the respective samples was dispersed in $25 \mathrm{~mL}$ porogen through sonication for about $1 \mathrm{~h}$. The sedimentation of the samples was closely monitored at particular time intervals $(0,1,24,1$ week, and 1 month).

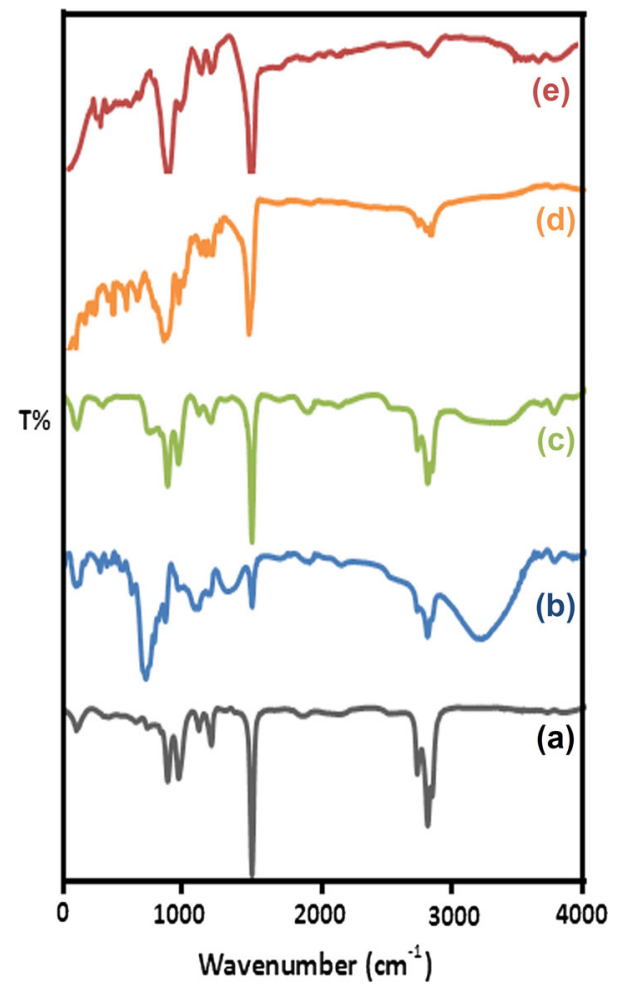

Fig. 2 FTIR spectra of $a$ purified MWCNT, $b$ MWCNT-COOH, $c$ MWCNT- $\mathrm{CH}=\mathrm{CH}_{2}, d$ MWCNT-MIP before washing and $e$ after washing

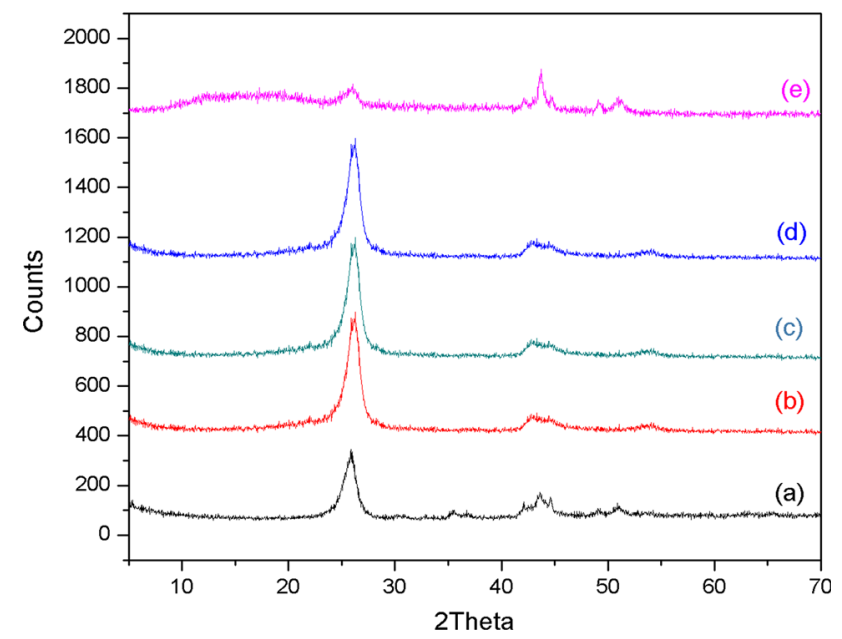

Fig. 3 Powder X-ray diffraction patterns of $a$ MWCNT, $b$ MWCNT$\mathrm{COOH}, c$ MWCNT-COCl, $d$ MWCNT- $\mathrm{CH}=\mathrm{CH}_{2}$ and $e$ MWCNTMIP

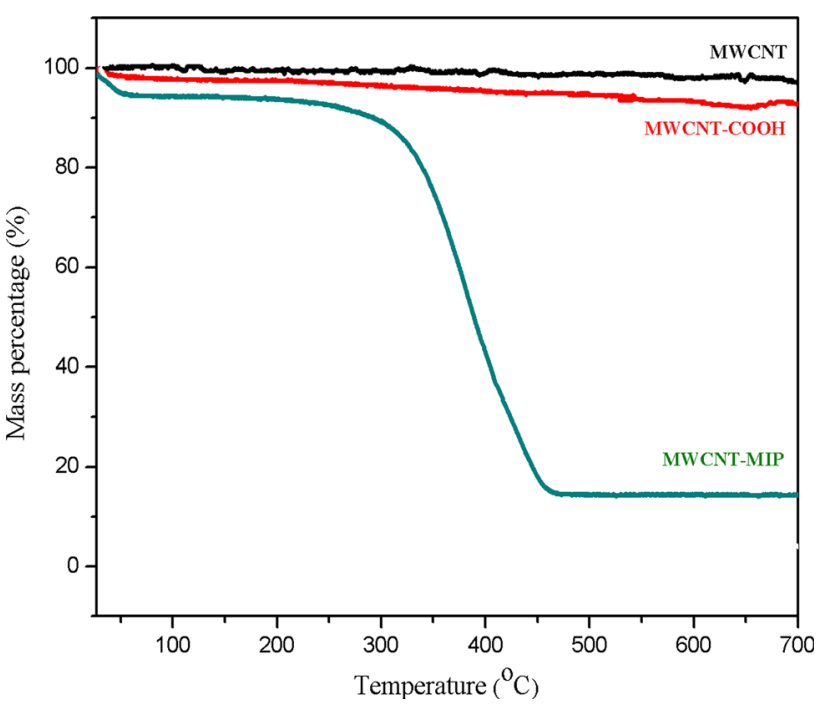

Fig. 4 TGA curves of MWCNT, MWCNT-COOH and MWCNTMIP (heating rate of $10{ }^{\circ} \mathrm{C} / \mathrm{min}$ from room temperature to $700{ }^{\circ} \mathrm{C}$ under $\mathrm{N}_{2}$ atmosphere)

\section{Results and discussion}

\section{Characterization}

Figure 2 shows the FTIR spectra of purified, acid and vinyl-functionalized carbon nanotubes and MWCNT-MIP before and after template extraction. The spectrum (a) exhibits the characteristic peaks of purified MWCNT such as a strong band at $1737 \mathrm{~cm}^{-1}$ corresponding to the $\mathrm{C}=\mathrm{O}$ stretching vibrations and a peak at $2928 \mathrm{~cm}^{-1}$ due to the asymmetric stretching vibration of $\mathrm{C}-\mathrm{H}$. The presence of new peaks in the spectrum of acid-processed MWCNTs (b) at 3300,1581 and $1352 \mathrm{~cm}^{-1}$ are due to the functional 
Fig. 5 Scanning electron micrographs of a MWCNT, b MWCNT-COOH,

c MWCNT-NIP, d MWCNTMIP
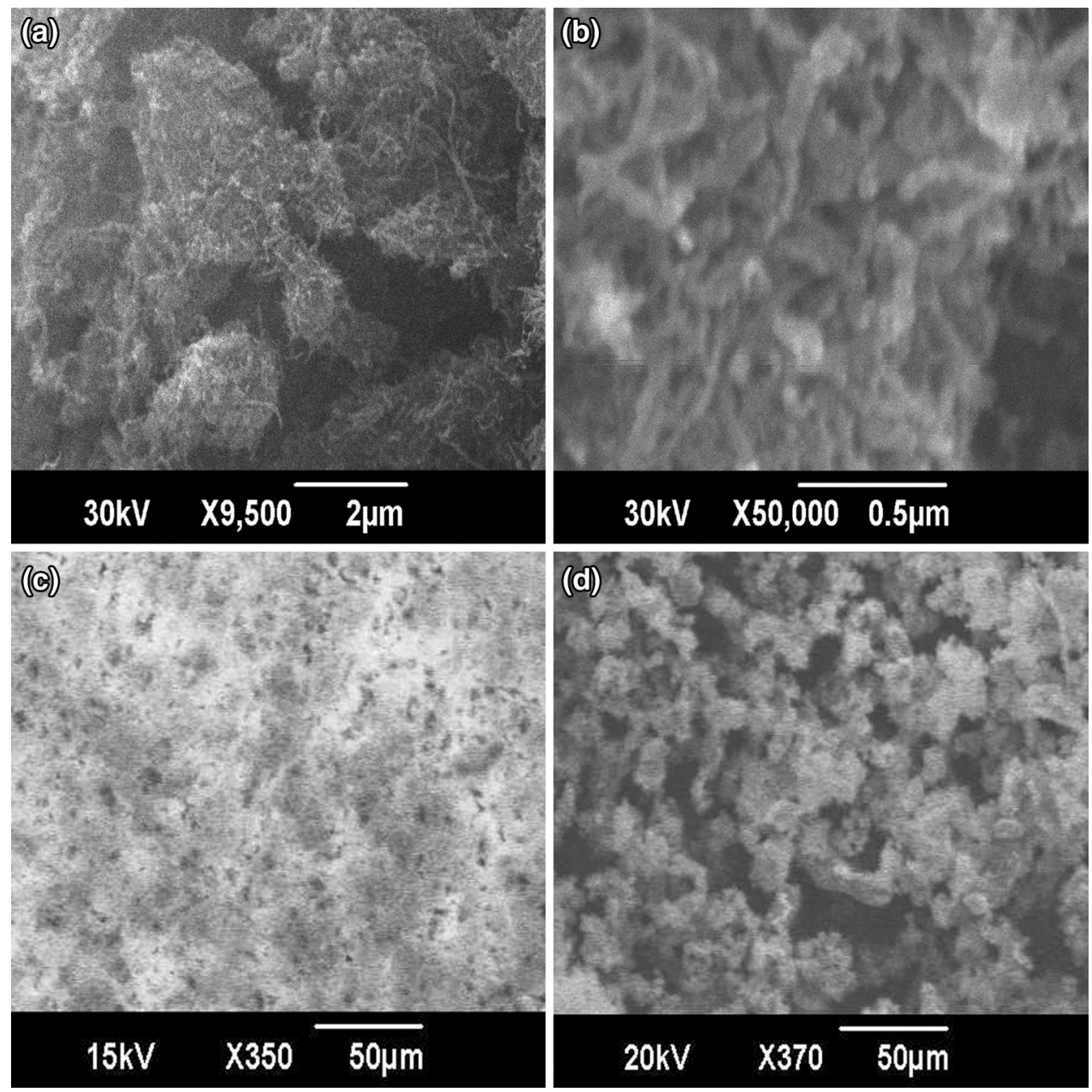

Fig. 6 TEM images of a MWCNT and b MWCNTMIP
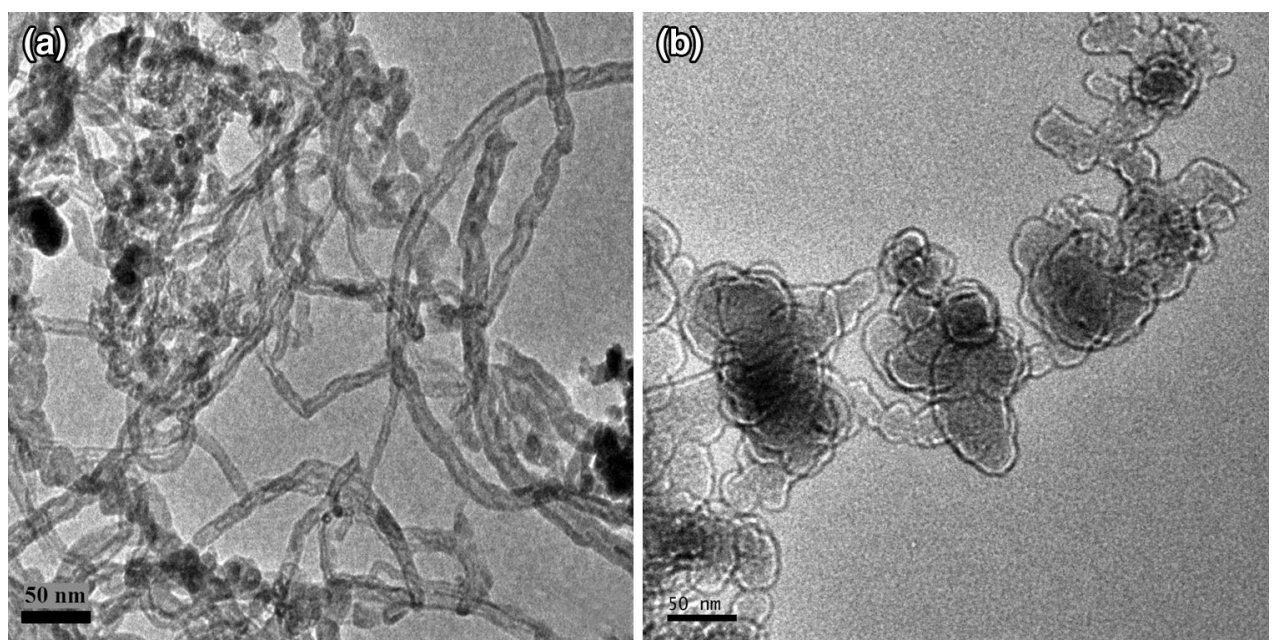

groups $-\mathrm{OH},-\mathrm{COOH}$ and the $\mathrm{C}-\mathrm{O}$ stretching vibrations of the carboxyl group, respectively, which were incorporated on acid treatment. A strong peak associated with ether linkage around $1166 \mathrm{~cm}^{-1}$ was observed in the spectrum of vinyl-functionalized MWCNT (c). The presence of this peak suggests that HEMA is coupled to MWCNT through the -O- atom. MWCNT-MIP before washing (d) showed a broad peak ranging from 3500 to $3300 \mathrm{~cm}^{-1}$ due to the 


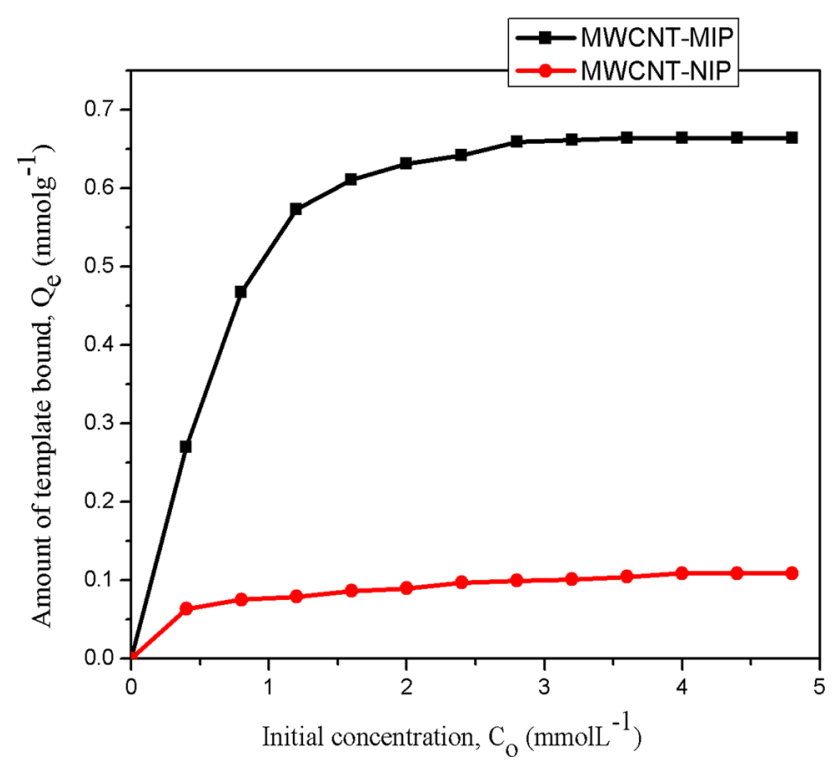

Fig. 7 Adsorption isotherms of imprinted and non-imprinted polymers (amount of polymer $10 \mathrm{mg}$; volume $8.0 \mathrm{~mL}$; concentration of S-IBU from 0.4 to $4.8 \mathrm{mmol} \mathrm{L}^{-1}$ )

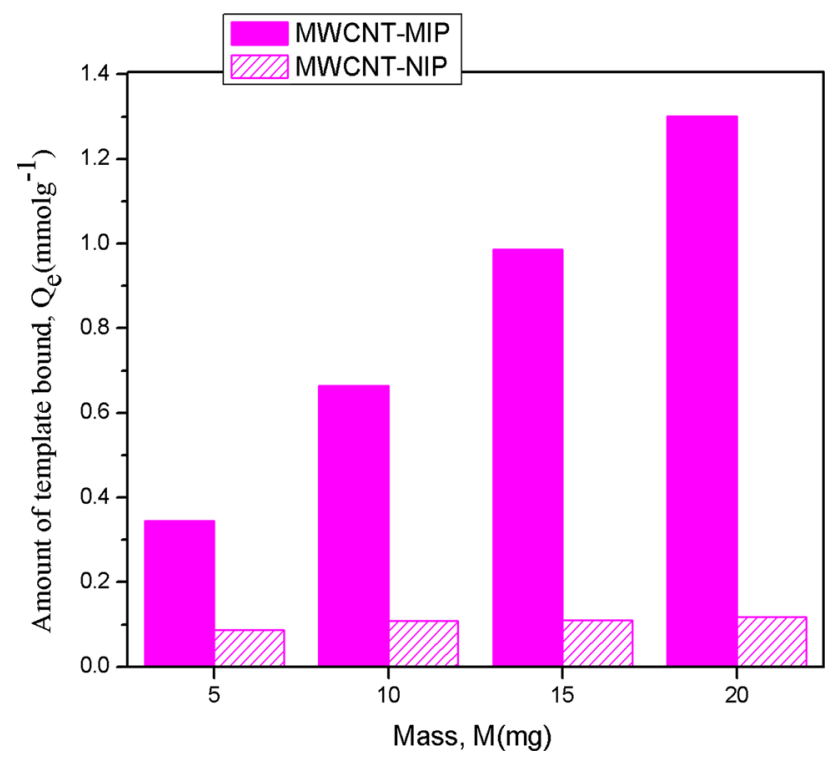

Fig. 8 Effect of adsorbent dosage on template bound (amount of polymer varies from 5 to $20 \mathrm{mg}$; volume $8.0 \mathrm{~mL}$; concentration of $\mathrm{S}$-IBU $4 \mathrm{mmol} \mathrm{L}^{-1}$; binding time $4 \mathrm{~h}$ )

carboxylic acid $-\mathrm{OH}$ stretch, which was absent in the spectrum of MWCNT-MIP after washing (e). The characteristic peak of S-ibuprofen at $1704 \mathrm{~cm}^{-1}$ representative of the carboxylic acid carbonyl stretching unit was also observed in (d). All these point out the successful embedding of S-IBU within the nanostructured sorbents.

Figure 3 shows the XRD patterns of MWCNT, MWCNT-COOH, MWCNT-COCl, MWCNT- $\mathrm{CH}=\mathrm{CH}_{2}$ and MWCNT-MIP. In the $2 \theta$ range of $20^{\circ}-70^{\circ}$ the X-ray

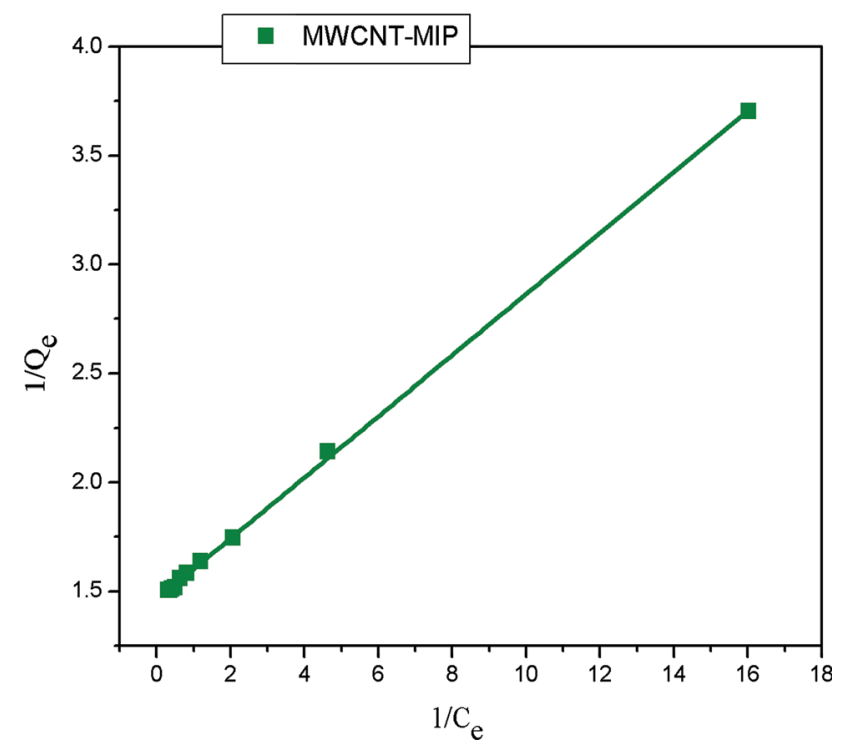

Fig. 9 Langmuir plot for adsorption of S-IBU by MWCNT-MIP (amount of polymer $10 \mathrm{mg}$; volume $8.0 \mathrm{~mL}$; concentration of S-IBU $0.4-4 \mathrm{mmol} \mathrm{L}^{-1}$; binding time $4 \mathrm{~h}$ )

diffractogram of MWCNT showed two crystalline peaks at $25.8^{\circ}$ and $43.7^{\circ}$ which are highly characteristic of hexagonal graphitic structure. Even after acid functionalization, the carbon nanotubes showed the aforementioned peaks indicating its retainment of crystallinity. It was further supported by the XRD patterns of MWCNT-COCl and MWCNT- $\mathrm{CH}=\mathrm{CH}_{2}$ which also showed the sharp crystalline peaks. The XRD pattern of MWCNT-MIP also preserved the crystallinity imparted by MWCNTs but the peaks were with less intensity owing to the encapsulation by the polymer layer. The presence of broad peaks at $2 \theta=15^{\circ}$ suggested the complete scattering of X-ray beams by the amorphous polymer part in MWCNT-MIP.

Thermogram of purified MWCNT showed a linear pattern up to $700{ }^{\circ} \mathrm{C}$ indicative of its high thermal stability (Fig. 4). However, MWCNT-COOH showed a continuous and non-apparent weight loss $(8.3 \%)$ due to the elimination of surface carboxyl groups from MWCNT. The successful inclusion of polymer onto the nanostructures resulted in MWCNT-MIP showing a dissimilar degradation pattern thereto of pure MWCNT. Initially there was a small dip in the TGA curve of composite MIP corresponding to the removal of solvent molecules trapped inside the polymer matrix. Degradation of the polymer chain over a broad temperature range of $300-450{ }^{\circ} \mathrm{C}$ demonstrates the extrastability gained by the polymer composite due to the presence of nanostructures. The residual mass of nanostructured MIP showed that $15 \%$ of the initial weight of MWCNT-MIP comprised multiwalled carbon nanotubes.

Purified MWCNTs showed characteristic tubular morphology with an average diameter around $6-8 \mathrm{~nm}$ in the 
Table 1 Adsorption isotherm parameters of MWCNT-MIP

\begin{tabular}{llllllll}
\hline Sample & \multicolumn{2}{l}{ Langmuir parameters } & & \multicolumn{2}{l}{ Freundlich parameters } \\
\cline { 2 - 3 } & $Q_{\mathrm{m}}\left(\mathrm{mmol} \mathrm{g}^{-1}\right)$ & $K_{\mathrm{a}}\left(\mathrm{L} \mathrm{mmol}^{-1}\right)$ & $R^{2}$ & & $n$ & $k_{\mathrm{f}}\left[\left(\mathrm{mmol} \mathrm{g}^{-1}\right)\left(\mathrm{L} \mathrm{mmol}^{-1}\right)^{1 / n}\right]$ & $R^{2}$ \\
\hline MWCNT-MIP & 0.684 & 10.428 & 0.999 & & 4.803 & 0.282 & 0.966 \\
\hline
\end{tabular}

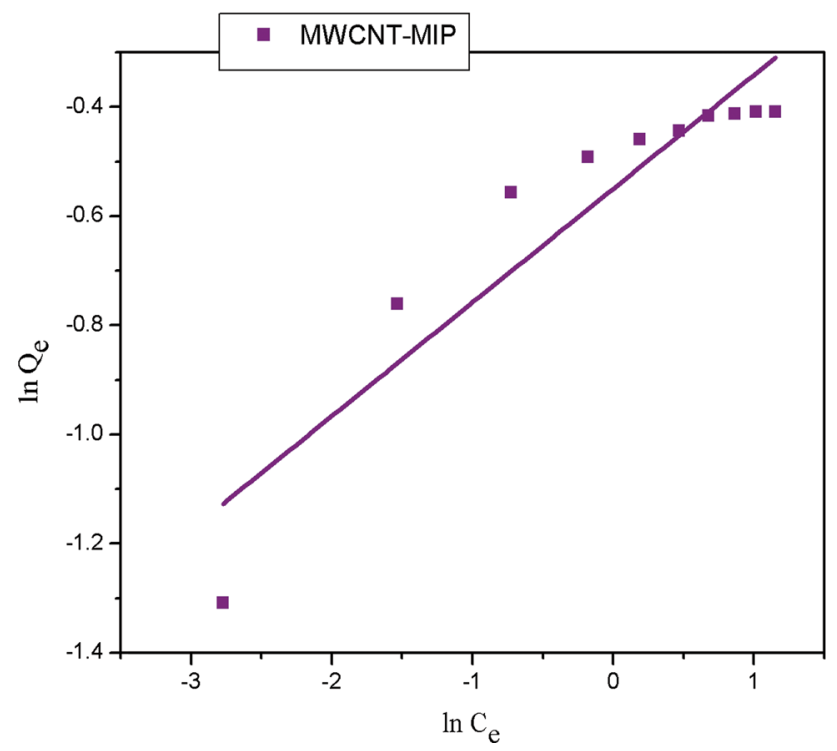

Fig. 10 Freundlich plot for adsorption of S-IBU by MWCNT-MIP (amount of polymer $10 \mathrm{mg}$; volume $8.0 \mathrm{~mL}$; concentration of S-IBU $0.4-4 \mathrm{mmol} \mathrm{L}^{-1}$; binding time $4 \mathrm{~h}$ )

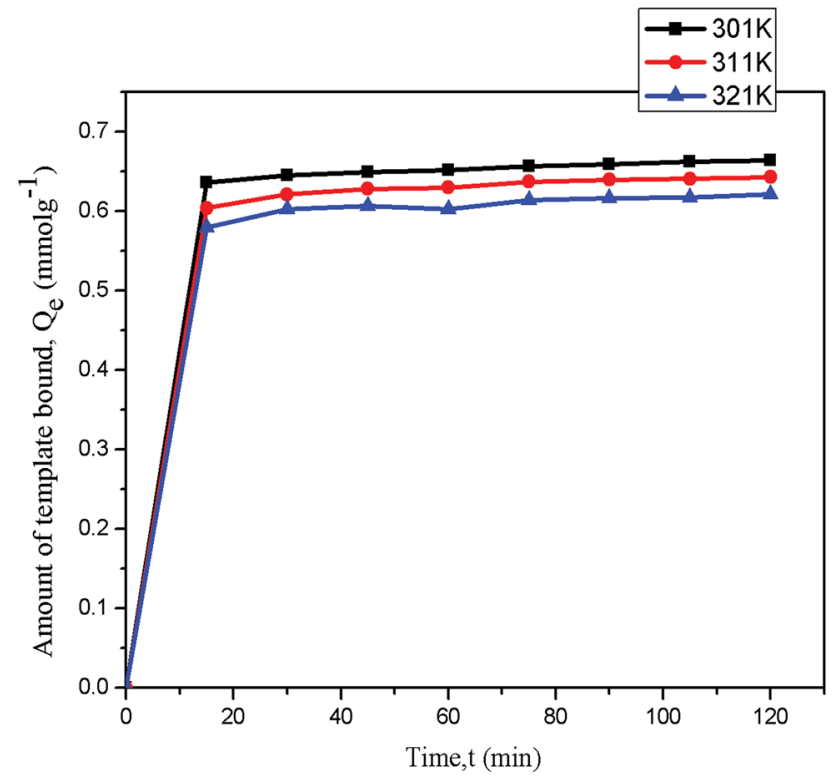

Fig. 11 Adsorption rate of S-IBU by MWCNT-MIP (amount of polymer $10 \mathrm{mg}$; volume $8.0 \mathrm{~mL}$; concentration of S-IBU $0.4-4$ mmol L ${ }^{-1}$, binding time $4 \mathrm{~h}$, temperature ranging from 301 to $321 \mathrm{~K}$ )

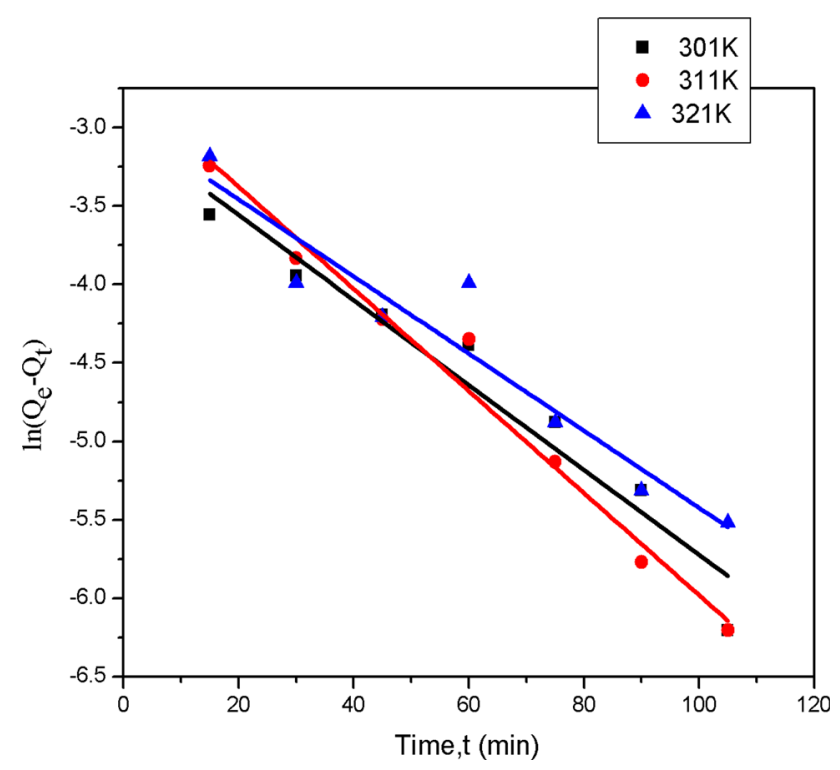

Fig. 12 Pseudo-first-order kinetic plot for adsorption of S-IBU by MWCNT-MIP (amount of polymer $10 \mathrm{mg}$; volume $8.0 \mathrm{~mL}$; concentration of S-IBU $4 \mathrm{mmol} \mathrm{L}^{-1}$, binding time $4 \mathrm{~h}$, temperature ranging from 301 to $321 \mathrm{~K}$ )

SEM micrographs (Fig. 5). It is also seen that these nanotubes are in a highly associated manner which accounts for their inherent undispersibility in solutions. After acid functionalization, the morphology was discovered to be saved with a slight increase in diameter. This shows that functionalization of MWCNTs do not essentially alter their nanofibrillar morphology. The surface-imprinted and nonimprinted sorbents also exhibited the morphology of carbon nanotubes with an increased diameter of about 30-32 nm. However, SEM micrographs of MWCNT-NIP showed smooth surfaces in contrast to the rough surface morphology exhibited by MWCNT-MIP. This may be due to the formation of template-specific binding cavities on MWCNT-MIP during the leaching out of print molecules from the polymer cast.

Morphologies of the purchased carbon nanotubes and synthesized composite sorbents were confirmed using HRTEM technique (Fig. 6). MWCNTs showed tubular morphology with a diameter ranging from 6 to $8 \mathrm{~nm}$ and a length of several micrometers. MWCNT-MIP retained the 
Table 2 Kinetic parameters from pseudo-first-order and pseudo-second-order equations for S-IBU adsorption onto MWCNT-MIP

\begin{tabular}{|c|c|c|c|c|c|c|c|c|}
\hline \multirow[t]{2}{*}{$\mathrm{C}_{\mathrm{o}}\left(\mathrm{mmol} \mathrm{L}^{-1}\right)$} & \multirow[t]{2}{*}{ Temperature (K) } & \multirow[t]{2}{*}{$Q_{\mathrm{e}, \exp }$} & \multicolumn{3}{|l|}{ Pseudo-first-order } & \multicolumn{3}{|c|}{ Pseudo-second-order } \\
\hline & & & $\left.\overline{Q_{\mathrm{e}, \mathrm{cal}}(\mathrm{mmol} \mathrm{g}} \mathrm{g}^{-1}\right)$ & $K_{1}\left(\min ^{-1}\right)$ & $R^{2}$ & $\left.\overline{Q_{\mathrm{e}, \mathrm{cal}}(\mathrm{mmol} \mathrm{g}} \mathrm{g}^{-1}\right)$ & $K_{2}\left(\mathrm{~g} \mathrm{mmol}^{-1} \mathrm{~min}^{-1}\right)$ & $R^{2}$ \\
\hline 4 & 301 & 0.664 & 0.0489 & 0.027 & 0.935 & 0.669 & 1.251 & 0.999 \\
\hline 4 & 311 & 0.643 & 0.0346 & 0.018 & 0.525 & 0.649 & 1.086 & 0.999 \\
\hline 4 & 321 & 0.621 & 0.0514 & 0.024 & 0.898 & 0.626 & 1.064 & 0.999 \\
\hline
\end{tabular}

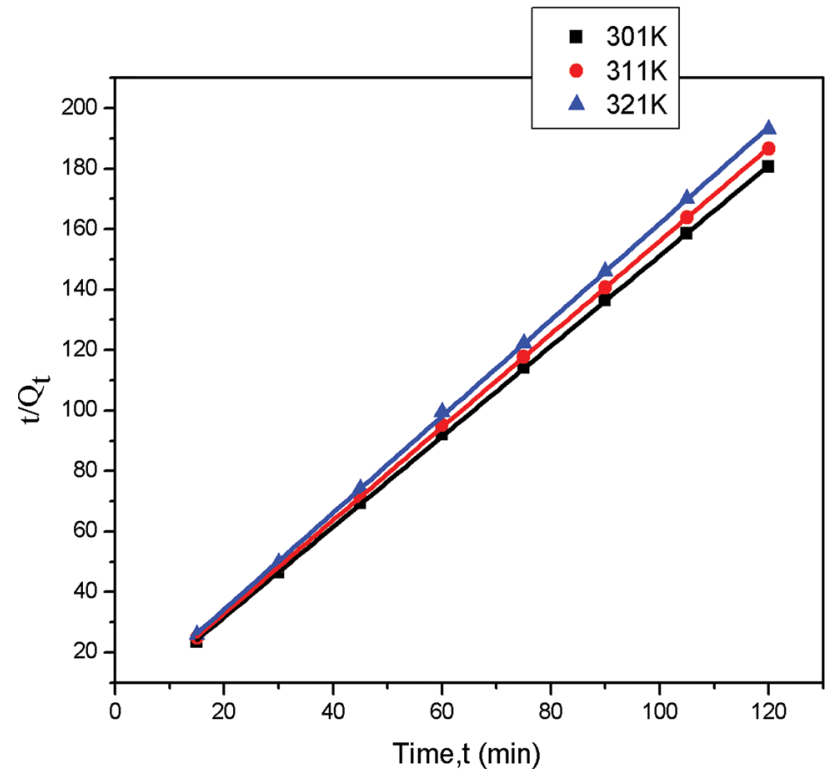

Fig. 13 Pseudo-second-order kinetic plot for adsorption of S-IBU by MWCNT-MIP (amount of polymer $10 \mathrm{mg}$; volume, $8.0 \mathrm{~mL}$; concentration of S-IBU $4 \mathrm{mmol} \mathrm{L}^{-1}$, binding time $4 \mathrm{~h}$, temperature ranging from 301 to $321 \mathrm{~K}$ )

characteristic nanotubular morphology of carbon nanotubes. The effective wrapping of polymer around the carbon nanotubes in MWCNT-MIP was further demonstrated by the increase in thickness to about 30-32 nm. This resulted not only in an increase in the template accommodation sites on the surface, but also in a higher homogeneity of the MWCNT-polymer system.

\section{Concentration study}

Figure 7 shows the impact of initial IBU concentration in the range $0.4-4.8 \mathrm{mmol} \mathrm{L}^{-1}$ on adsorption by the

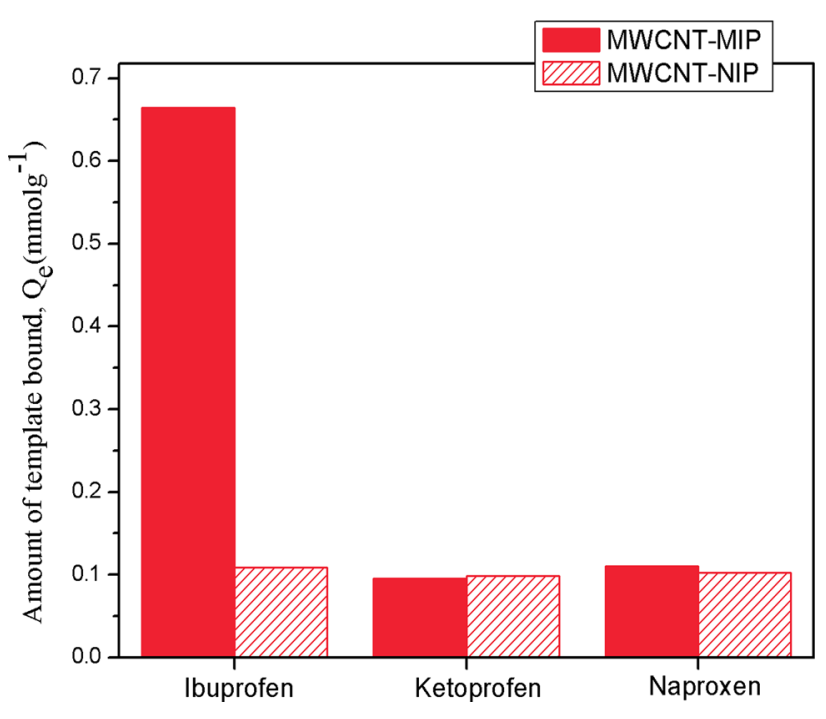

Fig. 15 Evaluation of the selectivity of the MWCNT-MIP compared with MWCNT-NIP for S-IBU, KET and NAP

imprinted and non-imprinted polymer composites. It was observed that the adsorption capacity increased from 0.2701 to $0.6644 \mathrm{mmol} \mathrm{g}^{-1}$ for MWCNT-MIP with an increase in initial template concentration and attains equilibrium at $4 \mathrm{mmol} \mathrm{L}^{-1}$. The boost in template adsorption by MWCNT-MIP may be due to the increased composite sorbent-template surface of contact with increasing concentration, resulting in greater number of valid collisions between the binding sites and template particles. The maximum adsorption capacity for MWCNT-MIP was found to be $83.6 \%$ higher than MWCNT-NIP which may be due to the deficiency in the number of functionally arranged template-specific 'memory cavities' in MWCNTNIP.<smiles>CC(C(=O)O)c1cccc(C(=O)c2ccccc2)c1</smiles><smiles>CC[SeH]1CCCCC1C(C)C(=O)O</smiles>

Fig. 14 Chemical structures of a S-IBU, b KET, and c NAP<smiles>CC(C)Cc1ccc(C(C)C(=O)O)cc1</smiles> 
Table 3 The distribution coefficient $\left(k_{\mathrm{d}}\right)$, selectivity coefficient $(k)$ and relative selectivity coefficient $\left(k^{\prime}\right)$ of MWCNT-MIP and MWCNT-NIP

\begin{tabular}{llllll}
\hline Sample & Drugs & $Q_{\mathrm{e}}\left(\mathrm{mmol} \mathrm{g}^{-1}\right)$ & $k_{\mathrm{d}}\left(\mathrm{mL} \mathrm{g}^{-1}\right)$ & $k$ & $k^{\prime}$ \\
\hline MWCNT-MIP & IBU & 0.664 & 0.1992 & - & 4.824 \\
& KET & 0.095 & 0.0243 & 1.577 \\
MWCNT-NIP & NAP & 0.110 & 0.0484 & 4.817 & - \\
& IBU & 0.109 & 0.0279 & - & - \\
& KET & 0.099 & 0.0314 & - \\
\hline
\end{tabular}

\section{Adsorbent dosage}

Figure 8 presents the effect of varying adsorbent dosages on template sorption. As expected, the removal efficiency was found to increase with increase in sorbent dosage which can be attributed to the increase in number of binding sites. MWCNT-NIP showed more or less same adsorption ability throughout the course of the experiment due to non-specific binding. The marked difference in the amount of S-IBU adsorbed by MWCNT-MIP and MWCNT-NIP exposes the absence of specific binding sites in the non-imprinted polymer composite.

\section{Adsorption isotherms}

A well-fit curve for Langmuir adsorption isotherm model was obtained for the adsorption isotherm data of MWCNTMIP (Fig. 9), signifying that the adsorption process was mainly monolayer on a homogeneous adsorbent surface. It was a linear plot based on the least square fit method with an $R^{2}$ value 0.999 and Langmuir constants $Q_{\mathrm{m}}$ and $K_{\mathrm{a}} 0.684$ $\mathrm{mmol} \mathrm{g}^{-1}$ and $10.428 \mathrm{~L} \mathrm{mmol}^{-1}$, respectively. Further, the experimental $\left(0.664 \mathrm{mmol} \mathrm{g}^{-1}\right)$ and theoretical $\left(0.684 \mathrm{mmol} \mathrm{g}^{-1}\right)$ maximum template adsorption capacities were found to substantiate the Langmuir model for MWCNT-MIP. The calculated isotherm constants and the corresponding correlation coefficients for MWCNT-MIP are shown in Table 1. The equilibrium data were further analyzed using the linearized form of Freundlich isotherm by plotting $\ln C_{\mathrm{e}}$ versus $\ln Q_{\mathrm{e}}$, as shown in Fig. 10. Here, the obtained experimental values and theoretical values are incompatible which again implies the suitability of the application of Langmuir model for the adsorption process of MWCNT-MIP (Table 1).

\section{Adsorption kinetics}

Initially rapid template adsorption occurs which slows down with time with the maximum adsorption occurring after $1.5 \mathrm{~h}$ at a capacity around $0.669 \mathrm{mmol} \mathrm{g}^{-1}$ (Fig. 11). This may be due to the presence of more binding sites on the surface of the sorbent which once template-bound becomes unavailable for further template binding. Pseudofirst and pseudo-second-order equations have been used for testing the kinetic data. The low correlation coefficient obtained for the pseudo-first-order adsorption rate expression (Fig. 12; Table 2) indicated that it was less appropriate. The theoretical values $\left(Q_{\mathrm{e}}\right.$ cal $)$ exhibited larger deviations from experimental data $\left(Q_{\mathrm{e}} \exp \right)$ (Table 2), again implying that the adsorption process does not follow fully the pseudo-first-order kinetics. The plot of pseudosecond-order adsorption rate expression (Fig. 13) gave a straight line $\left(R^{2}=0.999\right)$ suggesting that second-order kinetics is applicable and from the slope and the intercept of the plot, $Q_{\mathrm{e}}$ and $k_{2}$ were calculated, respectively. The results authenticated that the second-order kinetic equation provided a better evaluation as compared to the first-order kinetic equation. When the temperature was increased, values of kinetic parameters ( $k$ and $Q_{\mathrm{e}}$ ) decreased, showing that the process of adsorption was exothermic and the increased temperature resulted in the desorption of the template molecule from the adsorption sites (Jnr Horsfall and Spiff 2005).

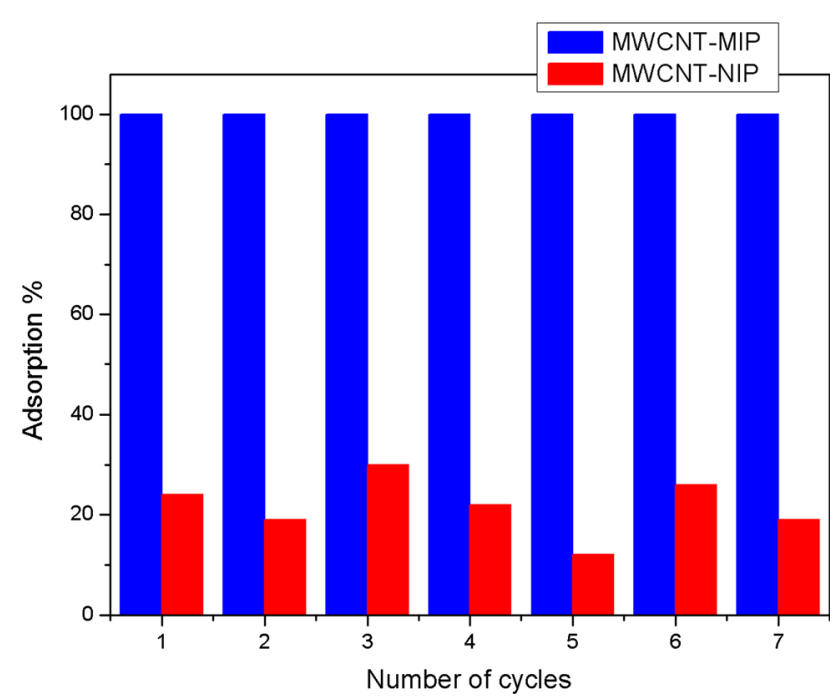

Fig. 16 Reusability test of MWCNT-MIP and MWCNT-NIP using chloroform as desorbing agent (amount of polymer $10 \mathrm{mg}$; volume $8.0 \mathrm{~mL}$; concentration of S-IBU $4 \mathrm{mmol} \mathrm{L}^{-1}$, binding time $4 \mathrm{~h}$ ) 

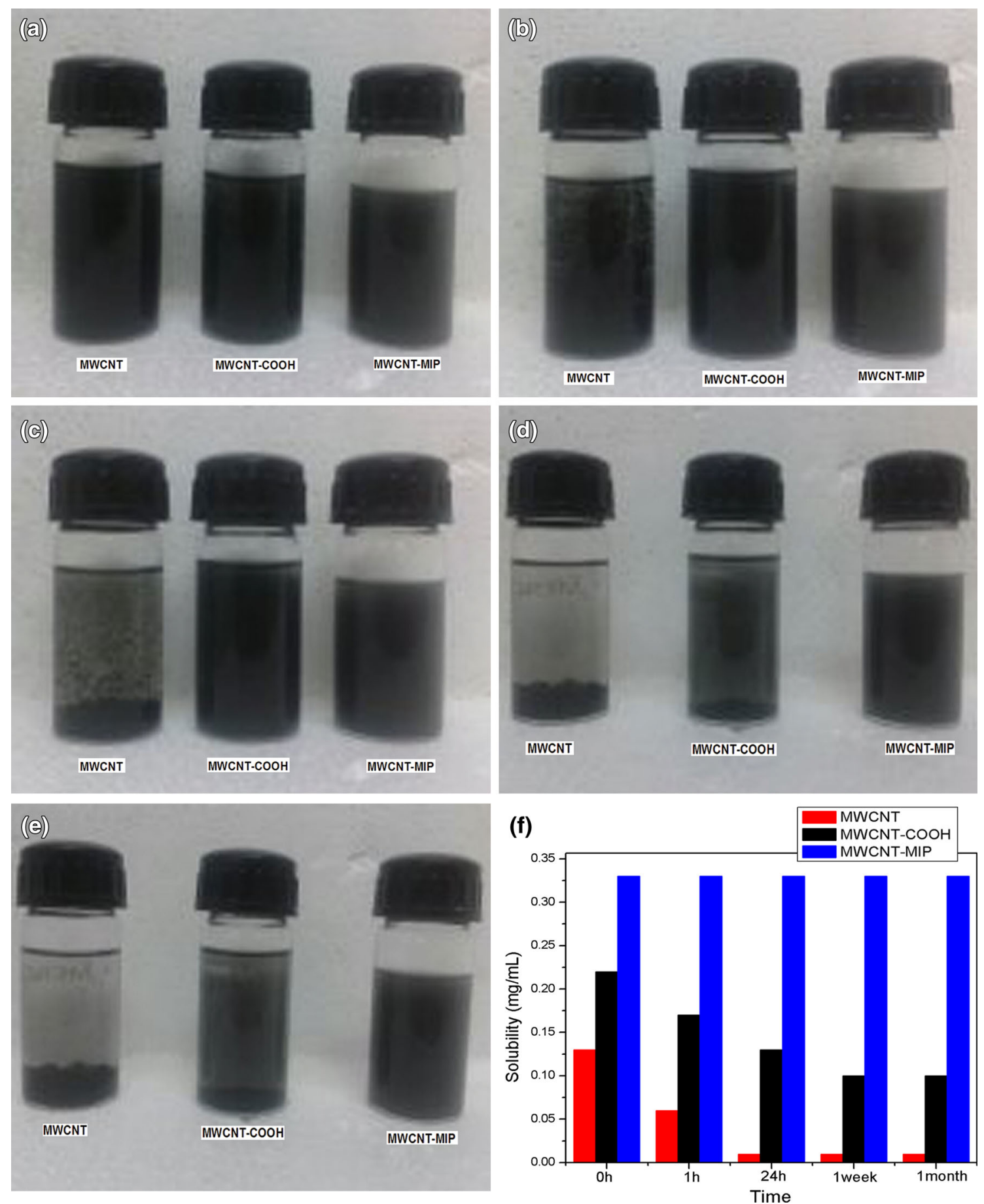

Fig. 17 Dispersibility of MWCNT, MWCNT-COOH, MWCNT-MIP in chloroform at a 0 h, b $1 \mathrm{~h}, \mathbf{c} 24 \mathrm{~h}, \mathbf{d} 1$ week, e 1 month and f solubility profile

\section{Selectivity studies}

The selective recognition capability of MWCNT-MIP and MWCNT-NIP towards S-IBU was demonstrated by selecting two structurally related compounds of S-IBU such as KET and NAP (Fig. 14). These compounds were supposed to act as interfering substances in the process of template rebinding. As is shown in Fig. 15 the nanostructured MIP had maximum binding capacity towards S-IBU than towards its structural analogues owing to the formation of template-specific and selective cavities on the composite surface. However, MWCNT-NIP showed almost similar adsorption capacities for all the three analytes due to the lack of exact imprint cavities. NIPs can 
bind compounds only by non-specific adsorption (Noir et al. 2007). These results suggested that depending on the interaction, size, shape and functionality of the template $(\mathrm{Li}$ et al. 2009), the molecular imprinting process created a micro-environment in the polymer matrix. Table 3 summarizes the values obtained for distribution coefficient $\left(k_{\mathrm{d}}\right)$, selectivity coefficient $(k)$ and relative selectivity coefficient $\left(k^{\prime}\right)$. So the synthesized MWCNT-MIP is a superior adsorbent for the selective separation of S-IBU from its structural analogues.

\section{Robustness and reusability}

The chloroform-washed regenerated MIP showed excellent rebinding capabilities up to seven sequential cycles of adsorption and desorption indicating that it retained a considerably 'long-term memory' of the target species (Fig. 16). MWCNT-NIP showed irregular trends of rebinding from the first cycle onwards as it is capable of only non-specifically interacting with the target molecule. This again substantiates the assumption of development of template-specific cavities in MWCNT-MIP.

\section{Solubility test}

The solubility profile and the images for the solubility test of MWCNT, MWCNT-COOH and MWCNT-MIP are shown in Fig. 17. Though complete dispersion for all the samples were obtained on sonication, MWCNT started to sediment faster and completely sedimented after $24 \mathrm{~h}$ indicating the absence of effective interaction between the nanotubes and solvent. However, MWCNT-COOH showed slightly increased dispersibility (Aghabozorg et al. 2010) owing to its functionalization which in turn increased its interaction, though weak, with the solvent. MWCNT-MIP, on the other hand, did not sediment and gave a stable dark suspension even after 1 month which clearly suggested the highly modified surface of the carbon nanotubes. The chemical modification of MWCNT reduces their agglomerating tendency thus retaining its dispersibility which was further supported by the solubility profile.

\section{Conclusions}

Molecular imprinted sorbent with a target-specific surface was fabricated for the effective separation of S-IBU from its structurally related compounds. The effect of initial template concentration, adsorbent dosage, time of contact, etc., on the rebinding capacity was studied in detail. The well-fit curve of Langmuir adsorption isotherm indicated a homogeneous distribution of binding sites with a monolayer adsorption of S-IBU within the MWCNT-MIP composite. The rate of kinetics of S-IBU adsorption was rapid in the case of MWCNT-MIP due to the availability of surface-imprinted cavities. The low cost, facile synthetic route and robustness of the surface-imprinted nanostructured MIP lend it a useful medium for S-IBU separation from its structural analogues which was also confirmed by its high selectivity coefficient.

Acknowledgments One of the authors (SMP) would like to thank University Grants Commission (UGC) for the financial assistance awarded as Rajiv Gandhi National Fellowship (RGNF).

Open Access This article is distributed under the terms of the Creative Commons Attribution 4.0 International License (http://creativecommons.org/licenses/by/4.0/), which permits unrestricted use, distribution, and reproduction in any medium, provided you give appropriate credit to the original author(s) and the source, provide a link to the Creative Commons license, and indicate if changes were made.

\section{References}

Aghabozorg HR, Kish SS, Rashidi AM (2010) Solubility of functionalized carbon nanotubes in different solvents. J Appl Chem Res Winter 3:29-33

Cao Y, Liu L, Xu W, Wu X, Huang W (2014) Surface molecularly imprinted polymer prepared by reverse atom transfer radical polymerization for selective adsorption indole. J Appl Polym Sci 131:40473. doi:10.1002/APP.40473

Ho Y-S (2006) Isotherms for the sorption of lead onto peat: comparison of linear and non-linear methods. Pol J Environ Stud 15:81-86

Ho YS, McKay G (1998) The kinetics of sorption of basic dyes from aqueous solution by sphagnum moss peat. Can J Chem Eng 76:822-827. doi:10.1002/cjce.5450760419

Jenkins AL, Yin R, Jensen JL (2001) Molecularly imprinted polymer sensors for pesticide and insecticide detection in water. Analyst 126:798-802. doi:10.1039/B008853F

Jnr Horsfall M, Spiff AI (2005) Effects of temperature on the sorption of $\mathrm{Pb}^{2+}$ and $\mathrm{Cd}^{2+}$ from aqueous solution by Caladium bicolor (Wild Cocoyam) biomass. Electron J Biotechnol 8:162-169

Kumar NA, Ganapathy HS, Kim JS, Jeong YS, Jeong YT (2008) Preparation of poly2-hydroxyethyl methacrylate functionalized carbon nanotubes as novel biomaterial nanocomposites. Eur Polym J 44:579-586. doi:10.1016/j.eurpolymj.2007.12.009

Kyzas GZ, Bikiaris DN (2014) Molecular imprinting for high-added value metals: an overview of recent environmental applications. Adv Mater Sci Eng 2014:8. doi:10.1155/2014/932637

Kyzas G, Fu J, Matis K (2014) New biosorbent materials: selectivity and bioengineering insights. Processes 2:419-440. doi:10.3390/ pr2020419

Kyzas GZ, Nanaki SG, Koltsakidou A, Papageorgiou M, Kechagia M, Bikiaris DN, Lambropoulou DA (2015) Effectively designed molecularly imprinted polymers for selective isolation of the antidiabetic drug metformin and its transformation product guanylurea from aqueous media. Anal Chim Acta 866:27-40. doi:10.1016/j.aca.2015.01.045

Lagergren S (1898) Zur theorie der sogenannten adsorption gelöster stoffe. K Sven Vetenskapsakad Handl 24:1-39

Lendoiro E, de Castro A, Fernández-Vega H, Cela-Pérez MC, LópezVilariño JM, Rodríguez MVG, Cruz A, López-Rivadulla M 
(2014) Molecularly imprinted polymer for selective determination of $\Delta 9$-tetrahydrocannabinol and 11-nor- $\Delta 9$-tetrahydrocannabinol carboxylic acid using LC-MS/MS in urine and oral fluid. Anal Bioanal Chem 406:3589-3597. doi:10.1007/s00216013-7599-1

Li Y, Li X, Dong C, Li Y, Jin P, Qi J (2009) Selective recognition and removal of chlorophenols from aqueous solution using molecularly imprinted polymer prepared by reversible addition-fragmentation chain transfer polymerization. Biosens Bioelectron 25:306-312. doi:10.1016/j.bios

McCluskey A, Holdsworth CI, Bowyer MC (2007) Molecularly imprinted polymers (MIPs): sensing, an explosive new opportunity? Org Biomol Chem 5:3233-3244. doi:10.1039/B708660A

Noir ML, Plieva F, Hey T, Guieysse B, Mattiasson B (2007) Macroporous molecularly imprinted polymer/cryogel composite systems for the removal of endocrine disrupting trace contaminants. J Chromatogr A 1154:158-164. doi:10.1016/j.chroma. 2007.03.064

Özcan AA, Demirli Ş (2014) Molecular imprinted solid-phase extraction system for the selective separation of sleuropein from olive leaf. Sep Sci Technol 48:74-80. doi:10.1080/01496395. 2013.814678

Pan J, Yao H, Xu L, Ou H, Huo P, Li XX, Yan Y (2011) Selective recognition of 2,4,6-trichlorophenol by molecularly imprinted polymers based on magnetic halloysite nanotubes composites. J Phys Chem C 115:5440-5449. doi:10.1021/jp111120x

Perreten V, Schwarz F, Cresta L, Boeglin M, Dasen G, Teuber M (1997) Antibiotic resistance spread in food. Nature 389:801-802. doi: $10.1038 / 39767$

Puoci F, Hampel S, Parisi O, Hassan A, Cirillo G, Picci N (2013) Imprinted microspheres doped with carbon nanotubes as novel electroresponsive drug-delivery systems. J Appl Polym Sci 130:829-834. doi:10.1002/app.39212

Rezaei B, Rahmanian O (2012) Direct nanolayer preparation of molecularly imprinted polymers immobilized on multiwalled carbon nanotubes as a surface-recognition sites and their characterization. J Appl Polym Sci 125:798-803. doi:10.1002/ app. 35383

Shen J, Hu Y, Qin C, Ye M (2008) Layer-by-layer self-assembly of multiwalled carbon nanotube polyelectrolytes prepared by in situ radical polymerization. Langmuir 24:3993-3997. doi:10.1021/ la703957t

Sooraj MP, Mathew B (2014) Structure-specific sorbent based on nanostructures for selective recognition of cimetidine from its structural analogues. J Appl Polym Sci 131:40947. doi:10.1002/ APP. 40947

Turner NW, Jeans CW, Brain KR, Allender CJ, Hlady V, Britt DW (2006) From 3D to 2D: a review of the molecular imprinting of proteins. Biotechnol Prog 22:1474-1489. doi:10.1021/ bp060122g

Vasapollo G, Del Sole R, Mergola L, Lazzoi MR, Scardino A, Scorrano S, Mele G (2011) Molecularly imprinted polymers: present and future prospective. Int J Mol Sci 12:5908-5945. doi:10.3390/ijms12095908

Whitcombe MJ, Alexander C, Vulfson EN (1997) Smart polymers for the food industry. Trends Food Sci Technol 8:140-145

Wren SP, Nguyen TH, Gascoine P, Lacey R, Sun T, Grattan KTV (2014) Preparation of novel optical fibre-based cocaine sensors using a molecular imprinted polymer approach. Sens Actuators B 123:1180-1194. doi:10.1016/j.snb.2013.11.071

Zarejousheghania M, Fiedlera P, Moderb M, Borsdorfa H (2014) Selective mixed-bed solid phase extraction of atrazine herbicide from environmental water samples using molecularly imprinted polymer. Talanta 129:132-138. doi:10.1016/j.talanta.2014.05. 034

Zhang H, Zhou W, Wang H, Wang Y, He F, Cheng Z, Li H, Tang J (2012) Selective separation and analysis of $\mathrm{Pb}$ (II) using a new surface imprinted multi-walled carbon nanotubes combined with AAS. J Anal Sci Methods Instrum 2:60-67. doi:10.4236/jasmi. 2012.22012 